\title{
Food Safety in the Context of the European Union
}

Please cite this article as:

Dinu, V., 2018. Food Safety in the Context of the European Union. Amfiteatru Economic, 20(47), pp. 5-7.

Food safety is a component of food security. According to Codex Alimentarius, food safety is "assurance that food will not cause harm to the consumer when it is prepared and/or eaten according to its intended use". Food products - processed or fresh - sold to final consumers must not affect their health as a result of direct consumption or processing, depending on the intended purpose of each. In order for a food product - unprocessed, partially or totally processed or newly created - to be safe, it must necessarily fulfil three conditions: to have innocuousness, to be salubrious, not to endanger the human body, that is the normal and healthy consumer; to have nutritional and energy value; food nutrients to be available for the body.

Both the European and the national general regulatory frameworks on food safety set the consumer's right to a safe diet. The normative acts adopted by the European Union (EU) are aimed at harmonizing national food safety standards so that the free movement of food products can be achieved as efficiently as possible. In this respect, the European Union has developed a rich legislative body on food safety, animal health and welfare, and plant health, which is binding in all EU countries.

The EU wants to ensure that its citizens have access to safe and nutritious food products from healthy plants and animals. As a result, protecting human, animal and plant health at every stage of the production process is a key priority of economic and public health policies. At the same time, it aims to ensure the proper functioning of the food industry - the most important employer and production sector in Europe.

Ensuring food security in the European Union is a cross-border issue, as many of the food products we consume come from other countries. The European Union is a single market and products, including food can circulate freely within its territory. Thus, food is not marketed exclusively in one country, competition is thus growing, and consumers have a much wider range of products at lower prices. On the other hand, the single market also requires the development by the EU of the most important rules on food quality and safety.

Through its policy, the EU protects health throughout the food chain - that is, at every stage of the production process, from the farm to the consumer - by preventing food contamination and promoting food hygiene, food information and the health and welfare of animals and plants. Through its food policy, the EU aims to:

- ensure that food and animal feed is safe and nutritious;

- ensure a high level of animal health and welfare and plant protection;

- ensure adequate and transparent information on the origin, content, labelling and use of food products.

Vol. $20 \cdot$ No. $47 \cdot$ February 2018 
Taking into consideration the aspects mentioned above, in the Amfiteatru Economic Journal no. 47/2018 we present original research papers on food safety in an European, national and global context, bringing to the forefront a series of issues related to: food labelling and consumer information in the context of food quality and safety; food safety management; guaranteeing food security in the context of globalization; counterfeit and contaminated products; the relationship between food safety and sustainable development, etc., as it is presented in the following paragraphs.

In the paper "Generation Y's perception of product origin and its labelling in the context of food quality and safety" a comparison is made as to how Generation Y consumers form the Czech Republic, the Slovak Republic and Poland are aware of food quality and safety, the origin of the products and their labelling in the context of food quality and safety. It is also noted that, in all the countries included in the study, there is a low level of awareness of the information presented on the products' label and the advantage of this information is not well understood.

The exploratory paper "Comparative analysis of baby food labelling in Hungary and in Romania: Consumers' perspective” aims to analyse the buying behaviour of mothers in Romania and Hungary regarding children's food, in relation to the information on the labels. The paper also provides important results for producers and decision-makers to improve the labelling of children's products in order to help consumers make better, healthier and safer choices for their children.

Regarding food safety management, the papers "Implementation of ISO 22000 in Romanian companies: Motivations, difficulties and key benefits" and "Comparative study of certification schemes for food safety management systems in the European Union context" bring to the forefront the motivations, benefits and constraints that may limit the implementation of an ISO 22000-based food safety management system, as well as a comparative study of certification schemes for food safety management systems, in an attempt to provide organizations with the opportunity to understand what type of quality management system is appropriate to their particular organizational framework.

Some of the most important issues with regard to food safety are labelling and informing consumers. In this respect, the articles on "Consumer food security and labelling intervention on food products through public policies in Romania" and "Consumer confidence from ClujNapoca metropolitan area in the food labelling system" highlight issues such as the implementation of coherent public policies on food safety, as well as the factors influencing the level of consumer's confidence in the information presented on the food products' labels and the frequency of reading this information.

Transformations of the contemporary agricultural paradigm have placed food security as one of the key elements of the European agricultural model, along with food security and rural development. The objective pursued in the paper "Food safety and security in Romania - An econometric analysis in the context of national agricultural paradigm transformation" is the analysis of the correlations between the food safety and food security dimensions in Romania, using an econometric approach based on nine fundamental variables, in order to highlight these phenomena. From this perspective, the achievement of food safety and security objectives involves the functional integration of all the components and activities associated with both food production and its related activities, namely: processing, transport, storage, marketing and final consumption. 
Using the example of the international honey trade network, the aim of the paper "Network analysis for the improvement of food safety in the international honey trade" is to demonstrate the possibilities of using network-based stochastic simulation methods to detect the proliferation of accidentally or deliberately contaminated or counterfeit food.

A qualitative marketing research interviewing managers from companies in the wine industry in Romania's vine-growing regions on "Food safety and sustainability - An exploratory approach at the level of the Romanian wine production companies" aims to identify and analyse the opinions on the necessity, timeliness and efficiency of implementing sustainable development strategies and practices in the wine industry, considering food safety is considered a component of sustainability. The research places the relationship between food safety and sustainability at the forefront, and the authors consider that such an association is relevant to the economic and social context of the European Union.

The core principle of EU security policy, a source of constraints that may limit the adoption of the standard in the food industry is the application of a "farm to consumer" approach that covers all sectors of the food chain: animal feed production, plant and animal health, animal welfare, primary production, food processing, storage, transport, retail sales, as well as food import and export.

The EU food safety strategy ensures the traceability of food products, even if it involves the necessity to cross the borders within the Union. Thus, trade can take place freely, and consumers have at their disposal a wide variety of foods to choose from. High safety standards are important for consumer health, and they apply to both EU and imported foods.

Editor-in-chief, Vasile Dinu 